is made also to the presumably Tertiary granite of Arran, whose intrusive character was so clearly appreciated more than a hundred years ago by Hutton.

The Pleistocene notes include some general remarks on the method of investigation of the deposits of this and Recent ages. These notes are followed by an excellent account of the Drifts near Uttoxeter. It is remarked that the prevalent drift of the higher ground is a red sandy loam, or more rarely clay, containing numerous rounded quartzite and other pebbles mainly derived from the Bunter. Evidence was obtained that in spite of its general resemblance to rain-wash the material is the local equivalent of the true boulder clay, and has had a similar derivation from the moving mass of land-ice by which the whole country has been covered. It is remarked that the movement of the ice has not been determined by the shape of the ground in the vicinity, nor by the presence of the elevated Carboniferous Limestone tract of the Weaver Hills, but has been consequent upon the pressure of the great ice-sheet which was piled over the lower ground to the westward and north-westward. The occurrence in new localities of marine shells in the Drift of North Staffordshire is likewise noticed. Further particulars are also given of the Glacial Drift in South Wales. The height to which this extends seems limited only by that of the ground. Not only till with glaciated boulders, but numerous striated rock-surfaces have been observed at heights ranging up to 2000 feet on the Old Red Sandstone. In the Isle of Man the Glacial series has been found by a deep boring to be of unusual thickness, apparently descending to between 470 and 500 feet below sea-level.

From various parts of Scotland observations on the Drifts are recorded. In Aberdeenshire there is evidence of the occurrence of blocks of the Glen Derry diorite on the hillside above Allanmore, at a distance of more than six miles to the south-east of the parent-mass. These blocks could not have been brought to their present position by the later or local glaciation, but must have been transported by the ice-sheet over ridges nearly 3000 feet in height. In Inverness-shire the high-level terraces of fuvio-glacial gravel have been traced to an elevation of rozo feet. Many observations have been made on the Drifts in Ross-shire and in the Black Isle. Again, in Skye it has been observed that at the epoch of maximum glaciation only the highest summits of the Cuillins stood above the ice. This is true also of Blaven, and probably of the Red Hills, though the crumbling granite of which these latter are composed is not so well fitted as the gabbro to retain evidences of glaciation.

In the southern counties of England, as well as in Scotland and Ireland, various notes have been made on Pleistocene and Recent deposits, on the "Head," claywith-flints, raised beaches, sand-dunes, peat and other accumulations.

The new railway-cuttings which have been examined are those made by the Great Western Railway Company between Stert, near Devizes, and Westbury, in Wiltshire, and those between Wootton Bassett, in Wiltshire, and Patchway, in Gloucestershire. Cuttings on the Great Eastern Railway between North Walsham and Mundesley are briefly noted.

In this abbreviated account of some of the leading observations recorded in the "Summary of Progress of tue Geological Survey for 1898 ," we have sufficiently indicated the work that is being done, and which we hope will be carried on until the whole country has been mapped as carefully as possible on the six-inch scale. Until that work is accomplished, it can never be considered that the more pressing work of the Survey has been carried out. Regarding this as necessary, and looking to the work already performed, it is not to be denied that a very great deal of the more important work of the Survey has yet to be done. This remark applies, not only to the maps, but to the explanatory memoirs so needful in illustration of each map. The list of publications which is appended to the report before us shows that a number of new memoirs have been issued, while others are in progress; and it is hardly necessary to add that the surveying alone will not supply the public needs if the maps are not accompanied as soon as possible with the memoirs which describe the facts and explain the structures depicted on the maps.

\section{SIR RICHARD THORNE THORNE, K.C.B., F.R.S.}

SANITARY science has suffered a severe loss by the death, on Monday, of Sir Richard Thorne Thorne, K.C.B., F.R.S., principal medical officer to the Local Government Board. As a guardian of the public health, he was largely responsible for the security of the United Kingdom against serious epidemics, and for the introduction of sanitary measures which have resulted in a diminution of mortality ; and as an investigator he made numerous important contributions to the science of preventive medicine.

Sir Richard Thorne Thorne was born at Leamington on October I 3, I $84 \mathrm{I}$, and was therefore fifty-eight years of age at the time of his death. From an obituary notice in the Times the following particulars concerning his career have been derived. He received his medical education at St. Bartholomew's Hospital, and obtained the membership of the Royal College of Surgeons in 1863. In $\mathrm{I} 866$ he became M.B. of the London University, taking a double first class, and for a short time he held some hospital appointments in London; but about 1870 he accepted office in the Medical Department of the Privy Council, which was afterwards transferred to the Local Government Board. In this capacity he continued for many years to discharge the routine work of the office, in the way of inspections and reports, until I 885 , when his mastery of the French language led to his selection as delegate of the British Government at a first International Sanitary Conference, which was held at Rome, and was followed by others at Venice, Dresden and Paris. In these conferences he took from the first a leading part, and was mainly instrumental in convincing the representatives of other Governments of the futility of quarantine and of the facility with which, notwithstanding the presence of infectious disease, commerce might be liberated from vexatious restrictions which had previously hampered it. In this way he became a conspicuous public benefactor, not of this country alone, but of many others; and he was appointed her Majesty's Plenipotentiary for signing the Sanitary Convention of Dresden in 1893 and that of Paris in 1894 . He early received the distinction of C.B., and that of K.C.B. was conferred upon him in 1897 , soon after he had succeeded the late Sir George Buchanan as the head of his department. He was a Crown member of the General Medical Council, vice-president of the Epidemiological Society, Fellow of the Royal Society and of the Royal College of Physicians, LL.D. of Edinburgh, Doctor of Science of the Royal University of Ireland, and held numerous foreign distinctions. Apart from his many official reports relating to the public health, he was the author of works on the progress of preventive medicine during the Victorian era (1887), the "Milroy" lectures on the natural history and prevention of diphtheria (I89I), and of the "Harben" lectures on the administrative control of tuberculosis (I898).

By these and other publications Sir Richard Thorne Thorne assisted scientific progress, and improved the conditions of public health. The influence of his works on national sanitation will long be felt.

NO. I 573, VOL. 6I] 